\title{
Ensino de arte e educação emancipatória face à arte contemporânea
}

\author{
Giovana Bianca Darolt Hillesheim* \\ Universidade do Estado de Santa Catarina
}

\begin{abstract}
Resumo
No intuito de desmascarar uma falsa incompatibilidade entre arte contemporânea e educação emancipatória, este estudo apresenta uma reflexão sobre os enfrentamentos conceituais necessários ao abordar a arte contemporânea no ensino de arte escolar. Para tanto, parte-se de uma descrição do entrelaçamento entre arte e mercado, considerando as nuances pós-modernistas desta relação. A sustentação do construto teórico se dá por meio do materialismo histórico-dialético, com ênfase em Terry Eagleton e Antonio Gramsci, na medida em que estes destacam a importância do pensamento histórico no processo de emancipação humana. A ascensão da mercadoria arte a partir dos anos 1970 e a privatização da cultura iniciada nos anos 80 são investigadas como dimensões importantes no redirecionamento do papel da arte e do artista na atualidade.
\end{abstract}

\section{Palavras-chave}

arte contemporânea; pós-modernismo; ensino de arte; educação emancipatória.

\section{Art teaching and emancipatory education in face of contemporary art.}

\begin{abstract}
In order to unmask a false conflict between contemporary art and emancipatory education, this study presents a reflection on the conceptual clashes needed to address the contemporary art in school art education. For this, one starts with a description of the intertwining of art and the market, considering the post-modernist nuances of this relationship. The theoretical construct is supported through the historical and dialectical materialism, with emphasis on Terry Eagleton and Antonio Gramsci, in so far as they highlight the importance of historical thinking in the human emancipation process. The rise of the art as commodity from the 1970s and the privatization of culture started in the 80 s are investigated as important dimensions in the redirection of the role of art and the artist today.
\end{abstract}

\section{Keywords}

contemporary art; postmodernism; teaching art; emancipatory education.

\footnotetext{
* Mestra e doutoranda em Artes Visuais no Programa de Pós-Graduação em Artes Visuais da Universidade do Estado de Santa Catarina/UDESC. Orientadora: professora doutora Maria Cristina da Rosa Fonseca da Silva. Membro do grupo de pesquisa Educação, Artes e Inclusão e da Rede Latino-americana de Investigadores em Formação de Professores de Artes - LAIFOPA. giovanabianca@yahoo.com.br
} 


\section{A produção artística contemporânea}

A conversão dos bens culturais em negócios de larga escala faz parte de um fenômeno ao qual o teórico Fredric Jameson (2006) nomina de capitalismo cultural. Refletir sobre a arte produzida em tempos de capitalismo cultural requer compreender que a mesma vem passando por uma série de deslocamentos simbólicos que mudaram a percepção do papel da arte e do artista na sociedade. Paira na contemporaneidade um rol de incertezas acerca das práticas artísticas e a desconfiança de que é o mercado quem vem validando o trabalho artístico atual. A facilidade da arte contemporânea em não somente ser absorvida por transações comerciais, mas em colocar seu potencial criador a serviço delas, levanta sérias suspeitas sobre a sua capacidade ontológica de plasmar consciências, evidenciando as perguntas: até que ponto a arte pode desempenhar um papel crítico? A cultura, em sua concepção mais ampla, se configura como a grande vertente econômica da atualidade?

Tendo em vista que as mudanças intituladas por Jameson de capitalismo cultural não se deram repentina ou isoladamente, é imprescindível vincular a progressiva valoração financeira da mercadoria artística à concepção que ganha corpo a partir do século XVII, qual seja, a ideia de arte como atividade humana especial fruto de uma capacidade superior do espírito. As nuances históricas desse processo são narradas com detalhes por Warnke (2001) ao investigar a política das cortes europeias que ofereciam aos artistas postos e honrarias em troca de uma representação visual que corroborasse na elevação da aura dos príncipes. Tais enredos são bastante conhecidos no mundo da arte, da mesma forma que também o são os infinitos subterfúgios usados por muitos artistas para subverterem tais submissões.

Este texto, porém, se dispõe a refletir sobre um contexto mais recente, a partir de 1970, onde o processo de ascensão mercadológica da arte passa a exercer um tipo diferenciado de influência na produção artística, a ponto de muitos críticos 
questionarem se a junção entre arte e mercado acarreta um abandono, por parte do artista, do papel contestador da arte em nome de um caráter provocativo.

De que modo o mercado está afetando a maneira como vemos a arte? De que modo ele afeta a maneira como os curadores e editores veem a arte? A atmosfera competitiva criada pelo mercado leva os artistas a produzir obras melhores ou a favorecer produtos vazios? (JERRY SALTZ in THOMPSON, 2012: 259).

Olhos atentos à história recente permitem perceber o crescimento meteórico do mercado de arte a partir dos últimos anos da década de 1970 e início dos anos 1980, período este que se alinha a uma guinada conservadora na política internacional. Os anos 1980 testemunharam muitos gestos artísticos de rebeldia sendo recodificados e transformados em procedimentos de marketing. Acerca desse processo, a especialista em cultura e arte contemporânea Chin-Tao Wu, em seu livro Privatização da cultura (2006), discute a cultura empresarial na Grã-Bretanha e nos Estados Unidos da América, a partir dos governos de extrema direita de Margaret Thatcher e Ronald Reagan.

A autora descreve o modo como a cultura contemporânea, em especial a arte, foi submetida a um processo de privatização e passou, simultaneamente, a assumir um novo discurso compatível com o universo empresarial. Empresas passaram a criar seus departamentos de arte e contratar curadores para apresentar suas próprias coleções, emulando ativamente o que era uma prerrogativa dos museus e galerias públicos. Tais empresas transformaram galerias e museus em veículos de relações públicas e conferiram novo status à política das premiações, elevando o mundo empresarial à condição de árbitro do bom gosto e da cultura, fato que foi possível a partir do momento que os dois governos, Thatcher e Reagan, alteraram significativamente o papel do Estado por meio de uma defesa agressiva da economia de livre mercado.

Concordando com Chin-Tao Wu, Trigo (2014) percebe em grande parte da arte contemporânea um discurso que advoga a descrença nas grandes narrativas e aposta no esgotamento dos valores absolutos da arte moderna, chancelando a ideia de 
que a verdade e o conhecimento são sempre relativos. Submetida ao mundo empresarial, as artes passaram a ser usadas para estimular o consumo e criar um ar de arrebatadora exclusividade. 0 trabalho artístico contemporâneo, ao encontrar acolhida e ressonância ideológica nos hotéis-cassino de Las-Vegas e nos shoppings de luxo, personalizando a decoração e brindando os clientes com exposições vip, produz espetáculos pseudo-críticos. Na mesma perspectiva de análise de Chin-Tao Wu e Trigo, Greffe ressalta que "os artistas passaram a ser agentes de reencantamento do consumo". (GREFFE, 2013: 236).

Em meio a esta guinada ideológica, os conselhos de administração dos museus, antes coordenados por abastados homens brancos de aproximadamente 60 anos, passaram, na década de 1980, a um novo formato de gerenciamento por meio de jovens empresários altamente competitivos e comprometidos na disseminação do pensamento neoliberal.

Como estas empresas procuram disseminar sua própria cultura dentro da sociedade? Estabelecendo uma relação entre suas imagens e seus produtos que contribua para definir as relações sociais cotidianas; disseminando sua própria cultura e fazendo referência à cultura de outros membros da sociedade. [...] Disseminar através da arte valores que elas consideram como sendo seus é legitimar um sistema, globalizando-o. Se a troca de bens materiais é local, a circulação de símbolos pode ser global. (GREFFE, 2013: 244).

A arte irmanada com a política cultural empresarial passou a apoiar-se de maneira mais evidente no pós-modernismo e sua des-diferenciação, fundindo as oposições entre estruturas sociais dentro do campo generalizado do consumo e criando uma osmose entre criatividade econômica e criatividade artística.

Entre as estratégias de legitimação de pensamento adotadas, as empresas inseriram no mercado de arte por meio de concursos artistas que, a princípio, se manifestam contra a globalização, ao serem inseridos no mercado, acabam justamente dando ênfase aos "benefícios de um mundo globalizado" por meio do respaldo que suas obras dão às empresas que organizam estes eventos. Tais prêmios são frutos de parcerias entre empresas comerciais e grandes instituições 
artísticas, o que os legitima: Hugo Boss com Guggenheim Museum, Bristish Petroleum com National Portrait Gallery são exemplos destas parcerias. (GREFFE, 2013: 248). Paulatinamente, quando expostas nestas coleções ou submetidas a veículos de publicidade das empresas, as obras artísticas vão perdendo sua capacidade crítica.

No mundo das premiações, um dos concursos mais visados é o Prêmio Turner de Arte Contemporânea, criado em 1984 no Reino Unido. O prêmio organizado pela Tatte Gallery, em Londres, é atribuído ao artista plástico britânico com menos de 50 anos que mais se destacar durante o ano. Em 2014 o vencedor do Prêmio Turner foi 0 artista irlandês Duncan Campbell, de 42 anos, que recebeu a quantia de 25 mil libras esterlinas (equivalente a aproximadamente 40 mil dólares), pelo filme/ensaio It For Others, exposto pela primeira vez no pavilhão escocês da Bienal de Veneza em 2013. O filme de Campbell faz uma crítica ao universo internacional da comercialização da arte africana e usa uma imagem que se tornou popular: uma fotografia de Joe McCann, comandante oficial do IRA abatido pelo exército britânico em 1972. A intensão do artista foi mostrar como as imagens podem ser transformadas em produtos da cultura de massas. Duncan Campbell é conhecido por trabalhos que questionam as estruturas de poder e lidam com temas complexos. O filme It For Others possui 54 minutos divididos em quatro capítulos, um deles faz alusão ao marxismo por meio de cenas de dança protagonizadas por um balé de figuras negras que representam as equações criadas por Marx em 0 Capital.

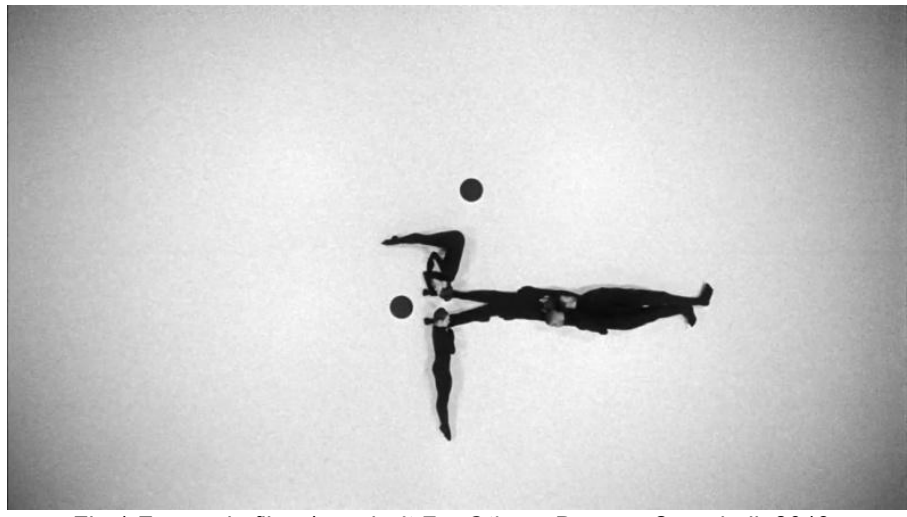

Fig.1.Frame do filme/ensaio It For Others. Duncan Campbell. 2013. 
Em 2015 foi a vez do coletivo de arquitetos Assemble vencer o prêmio Turner de Arte Contemporânea, outorgado pela Tate Gallery. O coletivo transformou uma dezena de casas devolutas em habitações modernas e úteis para a comunidade de um bairro degradado nos arredores de Liverpool. 0 júri declarou ter premiado 0 coletivo por ter mostrado como a prática artística pode ser capaz de conduzir e moldar questões urgentes através da arte, do design e da arquitetura. Jane Hall, uma das fundadoras do coletivo, declarou acerca da premiação: não importa se 0 que fizemos é arte ou não, o que importa são as pessoas. Segundo ela, há mais de 20 anos que o município tentava demolir aquela urbanização, tendo obrigado os moradores a sair e deixado as casas apodrecerem. Algumas pessoas se recusaram a abandonar a rua. O coletivo Assemble uniu esforços, criou uma cooperativa e, junto com a comunidade, reformou as casas, pintou fachadas, plantou jardins, limpou passeios.

O grupo Tate, instituição que dá legitimidade artística ao Prêmio Turner, recebe patrocínio empresarial, entre estes, o da British Petroleum, acusada de destruição do meio-ambiente em operações no Ártico e no Golfo do México. Acerca da polêmica em relação ao assunto, o diretor da instituição, Nicholas Serota, declarou: "Nenhum dinheiro é completamente sujo". Serota foi considerado pela revista britânica Art Review a pessoa mais poderosa do mundo das artes em 2014.

Para a crítica de arte Isabelle Graw (2013), uma das razões de as empresas se interessarem por arte reside na carga simbólica a ela atrelada. Associar a carga simbólica da arte às mercadorias produzidas por estas empresas equivale à transformação das mercadorias gerais produzidas pelo mundo empresarial em artigos de marca. Quanto mais se transforma os artigos gerais em artigos de marca, mais estes se parecem com a arte em termos ontológicos. Nesta perspectiva, a obra de arte assemelha-se a uma espécie de precursora dos artigos de marca. São artigos que geram experiência e produzem individualidade. Os artigos de marca buscam desenvolver uma personalidade, como as obras de arte. 
A arte filiada ao pensamento pós-modernista tende a celebrar as iniciativas individuais, a criatividade ilimitada, o poder de assimilação do diferente, enquanto abraça o repertório das micropolíticas, sejam elas de gênero ou raça, envolvendo questões ambientais ou sexuais, erradicação do trabalho infantil ou outras questões sociais não menos importantes. Por outro lado, quando voltada unicamente para a estetização e sedução de produtos, transforma-se em mero capital especulativo. A mudança de perspectiva da arte, seu crescente envolvimento com as micropolíticas e seu engolimento pelo mercado, corroboram para o emaranhamento entre arte e cultura, fazendo perder de vista que a arte é uma das muitas formas em que a cultura se materializa.

$\mathrm{Na}$ acepção gramsciana, apesar de cultura e arte não serem completamente independentes, são fenômenos com funções diferentes. A obra de arte que cumpre seu papel histórico é aquela que ao captar as contradições humanas não aliena a consciência histórica. A cultura, por sua vez, corresponde a uma categoria de transição no processo de elaboração da consciência. (GRAMSCI, 1989). Tanto os mecanismos de ampliação da consciência, quanto os mecanismos de repressão e embotamento, podem ser considerados processos culturais. Neste sentido, é oportuno lembrar que Gramsci depositava na cultura possibilidades de elevação da consciência, e não garantias; tudo depende dos bens culturais aos quais os indivíduos têm acesso.

Prejuízos conceituais acontecem, por exemplo, quando anúncios midiáticos confundem a arte com eventos gastronômicos, desfiles de moda, feiras de ornamentos, encontros de tatuadores, folguedos carnavalescos ou festivais de agronegócio. 0 emaranhamento promovido pela mídia causa a sensação de que estes eventos sociais suprem necessidades artísticas, ficando a diferenciação entre eles a cargo do gosto, unicamente. Entretenimento acaba sendo confundido com democratização da arte, questões totalmente diferentes. 
Alain Badiou (2002) ressalta que quanto mais a cultura de um país se encontra vinculada à indústria do entretenimento, maiores são as chances da arte perder espaço. Para Badiou, o mundo pós-moderno parece ser um mundo de adaptações avessas à filosofia, um mundo que acredita na gestão e na ordem natural dos acontecimentos. O pensamento pós-modernista cultiva o instantâneo, a não reflexão, as imagens midiáticas feitas para o consumo e não para a crítica. Para Terry Eagleton (2005), um dos mais vorazes críticos dedicados a descrever e desmascarar os meandros da cultura pós-modernista, a promiscuidade entre arte e cultura é prova de uma passagem da cultura politizada para a prática cultural. Em meio ao pensamento pós-modernista a arte foi, de maneira mais enfática, integrada ao processo geral de produção de mercadoria.

\section{Mas, afinal, o que é o pensamento pós-modernista?}

Segundo Eagleton (1998) é necessário entender que há diferença entre os termos pós-modernidade, restrito a uma delimitação histórica especifica, e pósmodernismo, uma forma de cultura contemporânea. De acordo com seu entendimento, a cultura pós-moderna questiona a noção clássica de verdade, subjetividade e emancipação, atribuindo um fim às grandes narrativas da história humana. Em contrapartida, defende um mundo contingente, diverso, instável e imprevisto que reúne um conjunto de culturas desunificadas.

Em relação às circunstâncias que deram origem à cultura pós-moderna, Eagleton pontua a nova forma de capitalismo surgida no Ocidente: descentralizado, voltado para a tecnologia, para o consumismo e para a indústria cultural. Neste novo formato de capitalismo, triunfam as indústrias de serviços, finanças e informações, gerando um comportamento cético defensor da política das identidades e uma arte superficial, autorreflexiva e eclética que obscurece as fronteiras entre arte elitista e cultura popular e entre arte e experiência cotidiana, tal como sugerem Chin-Tao Wu (2006), Greffe (2013), Trigo (2014), Graw (2013), Badiou (2002), entre outros.

Eagleton localiza como marco zero do pensamento pós-modernista a alardeada derrocada do bloco socialista no hemisfério Norte no final dos anos 80 , época que, 
conforme Chin-Tao Wu, vê nascer o início da privatização dos bens culturais. Diante de um novo sistema que parecia comprovar a derrota dos ideais esquerdistas, muitas pessoas que antes advogavam pela esquerda, passaram a procurar brechas nas quais pudessem agir pelas margens e adotaram como plataforma de atuação a defesa das minorias em um sistema que consideram inexpugnável. Assim, ser adepto da cultura pós-modernista implica em, além de desconsiderar qualquer possibilidade de autoridade benigna, empreender ações de protestos que possam ser acomodadas à ordem vigente, realizar pequenas transgressões para demonstrar não submissão ao poder e contratar serviços particulares, uma vez que o Estado não cumpre com seu papel. (EAGLETON, 1998).

Como pano de fundo à cultura pós-modernista está a total descrença na ideia de totalidade, uma vez que nenhuma grande ação política parece exequível àqueles que partilham desta concepção. As micropolíticas, portanto, foram se tornando a ordem do dia, pois para os adeptos do pós-modernismo não existiria um todo a ser transformado. Para Eagleton, a grande questão dos pós-modernistas ao negarem 0 conceito de totalidade é que admiti-la implicaria na existência de um sujeito para quem ela faria uma diferença prática. A antitotalidade resulta num consenso de que não é possível combater o todo e que é melhor apostar em projetos menos audaciosos.

Tanto quanto Terry Eagleton, a cientista política Ellen Meiksins Wood, também se dedica a analisar criticamente o pós-modernismo, principalmente em relação a como esta concepção de mundo lida com a linguagem, a cultura e o discurso, concebendo o conhecimento como algo naturalmente fragmentado. Para Ellen Wood (1999), a pós-modernidade é uma condição psicológica que corresponde a um período na bibliografia da intelectualidade de esquerda no Ocidente. Desta forma, a agenda pós-moderna começou a ser desenhada na idade áurea do capitalismo quando, diante de um clima de prosperidade e expansão econômica após a Segunda Guerra Mundial, a esquerda se viu obrigada a redefinir seus objetivos. 
A acepção de Ellen Wood em muito se assemelha a de Terry Eagleton, uma vez que ambos entendem que a crise na esquerda é simultânea à prosperidade capitalista. A crise seria, assim, nada mais que a consequência da apatia política que esvaziou os projetos emancipatórios. Os pós-modernos, de acordo com Wood, são insensíveis à história, pois negam a existência de estruturas ou de qualquer possibilidade de análise causal. Logo, se não há possibilidades de analisar as causas de um mundo opressivo, também não é possível almejar a emancipação humana. Para os pós-modernistas, portanto, o máximo que podemos esperar são resistências separadas e conciliações de interesses. Tanto as pequenas resistências, quanto os processos conciliatórios, incutem no cidadão a sensação de pertencimento a uma tribo. Portanto, é por meio da cultura pós-moderna que a individualidade e a universalidade se relacionam, ressaltando que o que de fato se universalizam são os desejos.

Até onde a universalidade dos desejos significa a democratização da cultura? Unificar desejos e necessidades é pretensamente inventar uma humanidade onde todos são simultânea e convenientemente iguais e diferentes. Quando as diferenças são aparentemente "respeitadas", uniformizadas e neutralizadas, passam a não mais existir, afinal, a ideia de que todos são diferentes acaba com 0 próprio conceito da diferença. A cultura universalizada seria uma anti-cultura, pois é o oposto do que constituiu historicamente as culturas: a afirmação de si pela diferença e pela oposição. "A cultura tornou-se totalmente indistinguível do capitalismo a partir dos anos 90 . É isso, realmente, parte do que queremos dizer com pós-modernismo". (EAGLETON, 2005: 78). 


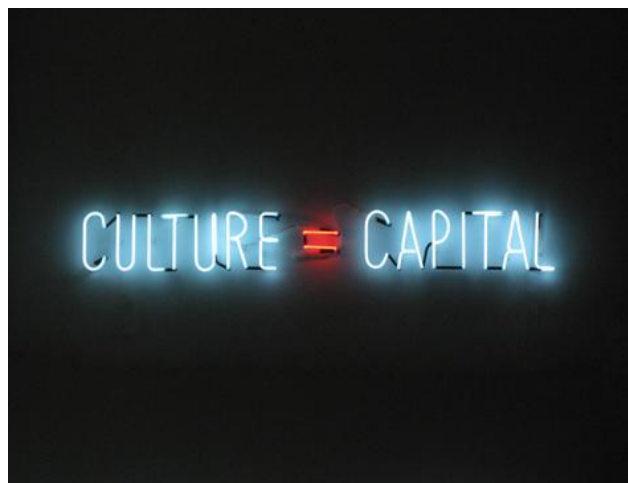

Fig.2. Alfredo Jaar. Culture = Capital. Neon. 2010.

Em meio à indiferenciação entre arte e cultura, cultura e capital, a arte contemporânea filiada ao pós-modernismo é confortavelmente assimilada pelo mercado. Ela vem acompanhada de uma pressão geral pelo político, entendendo este político como uma ação engajada voltada às causas consideradas ainda viáveis. A arte contemporânea pós-modernista celebra as ações individuais e a criatividade ilimitada. Em termos ideológicos, quanto mais a arte advoga pela emanação de um espírito livre que desenvolve uma atividade humana especial, mais compatível com a ideia de uma subjetividade pós-modernista não subordinada às necessidades do mundo do trabalho. Para o historiador de arte, Stallabrass (2015: 5).

De um modo estrutural, então, a ideia de que a consciência é materialmente formada e de que não é um exercício livre da vontade, é, em essência, incompatível com a ideologia do mundo da arte. [...] É possível imaginar um balanço das circunstâncias materiais que produzem a realidade atual dos trabalhos no mundo atual da arte contemporânea?

Como compreender a aparente incompatibilidade entre materialismo e arte contemporânea? Stallabrass recorda que, para Marx, as próprias contradições do sistema capitalista produziriam as formas mentais que permitiriam que 0 sistema fosse descrito e as contradições apreendidas. Quanto mais os princípios de liberdade, relatividade, soberania e excepcionalidade da arte são utilizados pelo mercado para estabelecer um consenso social ou fortalecer marcas, mais se torna evidente a determinação material da arte. 


\section{Por fim, um ensino de arte que corrobore com a emancipação humana}

O ensino de arte só faz sentido como instrumento para a emancipação humana na medida em que se acredita que à arte cabe plasmar consciências, como preconizava Gramsci (1989). A arte é práxis humana que humaniza os sentidos, sentidos estes historicizados, pois à medida que o homem faz arte não constrói apenas objetos, mas um sujeito para estes objetos, portanto a forma como lidamos com a arte é sempre influenciada pelo tempo em que vivemos. 0 que a submissão da arte ao mercado diz sobre a condição humana desta época? É possível que uma arte sedutora e seduzida, ajude a formar consciências?

É necessário ter em mente que a especificidade da arte dentro do universo cultural se dá na medida em que ela consegue captar os aspectos contraditórios da vida humana indo além das circunstâncias de sua gênese. Para Kosik, citado por Konder (2013), a durabilidade do conhecimento artístico decorre da interação entre passado, presente e futuro: o futuro como possibilidade e o passado como agente vivo na constituição do presente. Um ensino de arte profícuo deve favorecer a percepção de uma condição histórica particular da humanidade e estabelecer relações com a própria consciência individual.

Gramsci acreditava numa arte que estivesse ao mesmo tempo circunscrita numa fase histórica, coadunada e representativa da realidade humana, sem deixar de cumprir suas funções estéticas. Por funções estéticas entenda-se o modo como a arte se reinventa, como rompe sua sintaxe, como agride o já instituído. Há, portanto, um caráter político na função estética que não pode ser confundido com discursos temáticos representativos. A política na arte não depende da representação de substâncias ideológicas; é preciso pensar na arte como atividade política em si e não na inserção da política na arte. Neste sentido, talvez o maior ato de rebeldia que a arte possa propor na atualidade seja o resgate da consciência histórica. É pelo viés histórico que se percebem os aspectos que cercam a realidade para, então, compreendê-la. 
Walter Benjamin (1893-1940) entreviu a hiper-estetização da realidade contemporânea e sua concomitante valorização das experiências desarticuladas da memória. As experiências mencionadas por Benjamin, ou singularidades contemporâneas, como intitula Jameson (2005), podem ser percebidas no discurso pós-modernista por meio de um processo de presentificação, onde tudo acontece no momento presente por meio de "vivências": vivência artística, vivência gastronômica, vivência sonora, vivência turística, vivência corporal, vivência pedagógica, vivência estética, vivência espiritual... são vivências que buscam dar ao indivíduo a sensação de singularidade e valorizam a exclusividade momentânea - Acreditar num ensino de arte emancipatório envolve extrapolar o singular e 0 momentâneo; requer lembrar às pessoas que a compreensão do mundo continua sendo algo possível e importante.

Ensinar arte desvinculando-a da compreensão do mundo equivale a usar a arte como meio de privação da consciência de si. Da mesma forma, quanto mais se mistura arte e cultura, mais se configura um afastamento da consciência histórica. Sem consciência histórica não se evidenciam as contradições. Sem contradições a arte cai no limbo e se torna apenas mais um objeto estético em meio a tantos outros. O processo de capitalização da cultura inscreve na posteridade o que as pessoas deste momento histórico conceituam como arte. Como se produzem as necessidades culturais de nosso tempo? A arte é uma dessas necessidades?

Se o ensino de arte resultar em uma resposta afirmativa - "sim, a arte é uma necessidade" - caberão muitas outras perguntas: por que nem todos são atendidos nesta necessidade? Como a sociedade em que vivemos seleciona os indivíduos que terão suas necessidades atendidas? É possível, mediante o modelo de sociedade atual, 0 atendimento igualitário às necessidades humanas?

Se, por outro lado, o ensino de arte resultar em uma resposta negativa - "não, a arte não é uma necessidade" - caberão outros tantos questionamentos: A arte nunca foi uma necessidade? Em que momento a arte deixou de ser necessária? 0 
que substitui esta necessidade nos dias atuais? A quem interessa a "inutilidade" da arte?

\section{Considerações finais}

Este breve estudo procurou evidenciar a necessidade de desconstruir duas premissas que vem sendo tratadas como consenso: a primeira rotula toda arte contemporânea de arte pós-moderna e a segunda vê a busca pela emancipação humana como um retrocesso em relação à arte contemporânea. É preciso lembrar que arte contemporânea nem sempre é sinônimo de arte pós-moderna e que arte contemporânea e emancipação não são incompatíveis no ensino de arte, embora se admita que o capitalismo cultural induza ao olhar desinteressado, às ações individualizadas e à crença na criatividade como bem absoluto.

O enlace entre arte e mercado reconfigura muitas propostas artísticas durante 0 processo de produção, outras tantas no processo de circulação e até mesmo nas estratégias de consumo. A única saída para um ensino de arte com viés emancipatório é encarar a produção, a circulação e o consumo da arte contemporânea munidos com repertório histórico. Só assim será possível compreender 0 redirecionamento do papel da arte e do artista na atualidade e desmascarar falsas incompatibilidades.

\section{Referências}

BADIOU, A. Pequeno manual de inestética. Trad. Marina Appenzeller. São Paulo: Estação Liberdade, 2002.

EAGLETON, T. A ideia de cultura. São Paulo: Ed. UNESP, 2005. As ilusões do Pós-modernismo. Rio de Janeiro: Zahar, 1998.

GRAMSCI, A. Os intelectuais e a organização da cultura. Trad. Carlos Nelson Coutinho. 7. Ed. Rio de Janeiro: Civilização Brasileira, 1989.

GRAW, I. Cuànto vale el arte? Mercado, especulación y cultura de la celebridade. Trad. Cecilia Pavon y Claudio Iglesias. - Buenos Aires: Mardulce, 2013.

GREFFE, X. Arte e Mercado. São Paulo: lluminuras- Itaú Cultural, 2013.

JAMESON, F. Pós-modernidade: a lógica cultural do capitalismo tardio. São Paulo: Ática, 2006. 
Modernidade singular: ensaio sobre a ontologia do presente. Trad. Roberto Franco Valente. Rio de Janeiro: Civilização Brasileira, 2005.

KONDER, L. Os marxistas e a arte: breve estudo teórico-crítico de algumas tendências da estética marxista. 2. Ed. São Paulo: Expressão Popular, 2013.

STALLABRASS, J. A política do ensaio politico de catálogo. Revista ARS, São Paulo, ano 7, n 16, 2015.

THOMPSON, D. O Tubarão de 12 milhões de dólares: a curiosa economia da arte contemporânea. Trad. Denise Bottmann. BEI Comunicação, 2012.

TRIGO, L. A grande feira: uma reação ao vale tudo da arte contemporânea. $-2^{a}$ ed. - Rio de Janeiro: Record, 2014.

WARNKE, M. O Artista da Corte: Os Antecedentes dos Artistas Modernos; trad. Maria Clara Cescato. - São Paulo: Editora da Universidade de São Paulo, 2001.

WOOD. E. M. e FOSTER, J.B. Em defesa da história: marxismo e pós-modernismo. Rio de Janeiro: Jorge Zahar, 1999.

WU, Chin-Tao. Privatização da cultura: a intervenção corporativa nas artes desde os anos 80. Trad. Paulo Cezar Castanheira. Co-edição: Sesc e Boitempo Editorial, 2013. 